\title{
Language Problem in Educating Indigenous Children of Chittagong Hill Tracts in Bangladesh
}

\author{
Subarna Selim \\ Lecturer, Department of English, Bangladesh University
}

\begin{abstract}
Learning of Multilanguage through mother tongue is the most effective way for children to learn as it bridges the gap between mother tongue and other languages. A Lingua Franca or a single language of wider communication cannot be a substitute for the mother-tongue, and it should be avoided until the child fully acquires their mother-tongue (UNESCO,1953, p-11). Many educators and researchers identified the important necessary conditions for effective learning; such as: prior knowledge and understanding, integration of factual knowledge with conceptual frameworks, encouragement of profound understanding and giving students an active role in their learning process. A student's experiences and uniqueness are housed in their mother tongue, and thus mother tongue is a fundamental part of the prior knowledge necessary for students to move forward with their education. Many studies have demonstrated that use of students' first language in education has greater impacts not only on individual students but society as whole, as it: (a) increases access and equity, (b) improves learning outcomes, (c) reduces repetition and dropout rates. (Bender, 2005). In Bangladesh, although indigenous people hesitate in many parts of the country, Chittanong hill Tracts are haves of largest indigenous people in CHT include Chakma, Marma, Tripura etc. Children of these areas mostly communicate with one another in their own mother tongues. Indigenous people in Bangladesh are lagging behind the main stream Bangali speaking population in education, health and therefore in economic and social status. Mother language is important in identity and learning for tribal students, and needs to be encouraged and valued both in policy and practice for the educational achievement of tribal language students to improve. By making their learning activity based syllabus in Bengali and English including their native language tribal students can play a vital role in communication and development of the country.
\end{abstract}

\section{INTRODUCTION}

"Language is a matter of function four,

A means, a medium, a vehicle and a store"

The above quotation is like a prism of language to show different functions it performs. Firstly, it is a means of communication; people communicate their desires, feelings and day-to-day matters with others. Although voice, tone etc. are also means of communication, these have serious limitations these cannot fully communicate day-to-day complexities of modern lives. The extent of usefulness of a language depends on the extent of its development. A developed language has certain characteristics. It has grammar, syntax and vocabulary. A language without these basic characteristics is a rudimentary one and can only be a means of simple exchanges of information and thought. For communicative exchanges and particularly for education purposes, a language should have grammatical and other characteristics mentioned above. When developed as much as to have workable grammar and vocabulary, it can be used as a medium of education at least at the primary level. For exchanges of intricate complexities of life and dissemination of information, ideas and education at higher levels, besides having well developed grammar and vocabulary, a language should have a rich literature. Bengali, the national language of Bangladesh is such a language. At a still higher level(s) of study like postgraduate studies, and particularly research and development (R\&D) the appropriate referred language(s) is/are the national language and an international language. Knowledge gained through R\&D has worldwide appeal and hence needs to be stored.

In many countries throughout the world, there are concerns in educating children of their indigenous population /ethnic minorities/migrated labour force whose mother tongues are different from their national languages. For this reason, many of them take special care for education of the children of these people. In America, UK and France migrant labor force are quite large. In recent years 
Community schools in these countries are hiring trainers/ teachers from countries of their origin for teaching special course(s) and counseling children of these minorities using their mother tongues.

\section{OBJECTIVE}

This paper examines language problem of educating indigenous children of Chittagong Hill Tracts. In particular the paper has the following objectives:

1. Identification of the mother tongues of indigenous people of Chittagong Hill Tracts.

2. Identification suitability of the mother tongue for formal education of the indigenous children.

3. Looking into the existing medium of education at primary and higher levels of education of the indigenous children.

4. Gauging language-related other issues for education of indigenous children.

\section{Methodology}

The paper is based on the author's research report "....." which used information collected by a survey (sample survey) in the Chittagong Hill Tracts and secondary data (primary data) consisting of questionnaire-based information and information gathered from knowledgeable persons of the locality. The data analysis consists in interpretation of simple statistical results - average, bar diagram and pie chart etc.

For the study under consideration, a field level survey was undertaken. The survey was carried out by using questionnaire. The questionnaire was directed to the students, subject teachers (Bengali and English) and the Head of the institutions of the primary, secondary and tertiary levels.

In all, 74 students were interviewed that is answers from these students were taken according to the questions of the questionnaire. The survey was carried out at three districts - Rangamati, Khagrachori and Bandarban. 3 primary schools from Rangamati, 3 from Khagrachori and one from Bandarban were chosen for the purpose. In all 37 students were interviewed from primary level. For secondary level, 2 from Rangamati, 2 from Khagrachori and one from Bandarban were chosen. At this level 20 students were interviewed. At the tertiary level one class from each of these districts were surveyed. In this case, a total of 18 students were selected for interview.

The Pie-chart below shows Primary students (37), Secondary students (20) and Tertiary students (18) that were interviewed

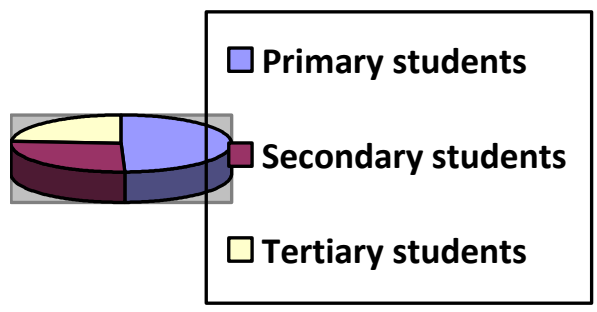

The bar-diagram below shows the percentage of Adibasi students (40\%) and Bangali students (60\%) in the schools visited in Rangamati.

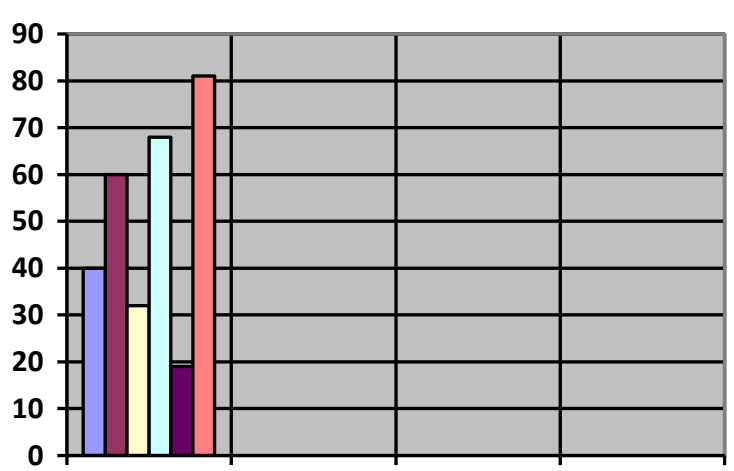

\begin{tabular}{|l}
$\square \%$ Indigenous students in \\
Rangamati \\
$\square \%$ Bangali students in Rangamati \\
$\square \%$ Indigenous students in \\
Khagrachori \\
$\square \%$ Indigenous students in Bangali \\
$\square \%$ Indigenous students in \\
bandarban \\
$\square \%$ Bangali students in bandarban \\
\hline
\end{tabular}


A total of 15 institutions (primary, secondary and tertiary) were visited for the survey purpose. The questionnaires were also directed to 15 Subject Teachers and 15 Head of the institutions and 15 parents to get their viewpoints on the issues.

It should be mentioned that the students from each class were selected randomly. The selection of subject teachers and the Head of the institutions dose not arise because they are predetermined.

By the nature of the survey, primary data (information) have been collected and utilized in this study. Since answers of the problems and issues raised in the questionnaire were described by the students, subject teachers, Heads and parents qualitatively. The study also uses secondary data which are mainly publication like books and reports. Thus the qualitative data as well as quantitative data form the basis of this study.

\section{Work Plan and Data Collection}

The study was conducted during August, 2014 - March, 2015. About four extra months were required to complete the study due to political and socio-economic condition of the country. Three data collectors were engaged for data collection and One Research Assistant was engaged to supervise the data collection process. The author herself also undertook visits to Rangamati and khagrachori to get insights of the problems involved.

\section{RigOUR AND TRUSTWORTHINESS}

Following the method of establishing rigour and trustworthiness of conducting the survey (Robinson and Lai, 2006), photographs and audio records of interviews were taken and documented.

\section{SuRVEy Results}

\subsection{Discussion}

Chittagong Hill Tracts is an inimitable area accordingly politically, ethnically and religiously in Bangladesh. Over the last forty years the indigenous communities have struggled for their recognition and autonomy in Bangladesh. At last the signing of the CHT Peace Accord between The Government of Bangladesh and The Parbatya Chattagram Jana Samhati Samiti . In this signing copy there was a strong recommendation of providing primary education through the mother tongue of the indigenous people of the CHT. Also free education should be provided to all students up to class X.

The survey data have been processed and the results are discussed in this section (The questionnaires are in the Appendix A).Survey results show that teaching and learning of students of indigenous people of CHTs at various pre-university levels have manifold problems. At all pre-university levels the main problem constitutes travel from their home to institutions - they come from long distance, crossing the rivers by boats and moving from hills to hills. As a result a large percentage of indigenous students' parent stop enrolls due to a lack of availability of schools within appropriate walking distance. In maximum field the quality education is not maintained for the indigenous students. The education programme has failed to recognize the specific learning which is needed especially in their mother tongue. The schools are not providing adequate teaching which is relevant, flexible or inclusive. The teachers emphasizes that with appointing the teachers from indigenous people who are applicable and training them by the various education training of government the quality and required teaching can be provided to the indigenous students.

Since there is no dormitory facilities, Jum cultivation being the main occupations, students are required to travel with their parents for as long as five to six months remaining absent from their educational institutions. There are not boarding schools or dormitory for the children. A few numbers is available where the parents do not want to send their children. They remain confused whether their traditional language would not be spoken by the children and their regular cultural practiced would be hampered if they stay in dormitories. Rather the parents preferred if the supervisor in dormitories are appointed from their locality it would be easy for them to practice their religious and cultural practice without any hamper. Also the government with the help of worldwide recognized NGOs could assist a handsome fund to build boarding school and dormitories in the remote areas of CHT. When parents would get these facilities they will also be eager to send their children for schooling. As a result local interest from the indigenous community and participation in education will be increased immensely day by day. 
Among other problems financial insolvency constitute a major factor of high drop outs at secondary level and particularly tertiary level. Government provides books at the primary level but this assistance is meager compared to their overall needs. NGOs operate only at high school levels supporting the education by providing educational aids like audio visual equipment and books.

At the private colleges there are facilities of dormitory, library, audio-visual aids and the teachers follow the modern teaching methodology because they are trained. But all these facilities are not available at the government colleges. At all levels of the pre-university institutions the language teachers are what is called borga- teachers. This means the main regular appointed teachers who are mainly from the plain land frequently remain absent from the institution and their regular duties are done by the teacher from local indigenous community. So as these local teachers are not trained enough the education of quality suffers.

The issue is effective education at schools and colleges. Children begin to listen and speak in their own mother tongues that is why they feel comfortable and at ease to learn in these tongues. Children generally learn other languages at later stages. So learning requires that the students are taught through mother languages most effectively.

There are as many as 45 indigenous ethnic groups which include Chakma, Marma, Tripura, Mro, Lusai etc. This means that there should be as many as 45 text books on these languages for effective learning of the entire ethnic group students. Except Chakma text books others have insufficient and mostly no such books at all. But unfortunately there is no organized effort to provide text books on local language text books. All these major causes of ineffective language teaching and learning at junior and mid level in CHTs are depicted pictorially below.

Major causes of ineffective language teaching and learning at junior and mid level in CHTs

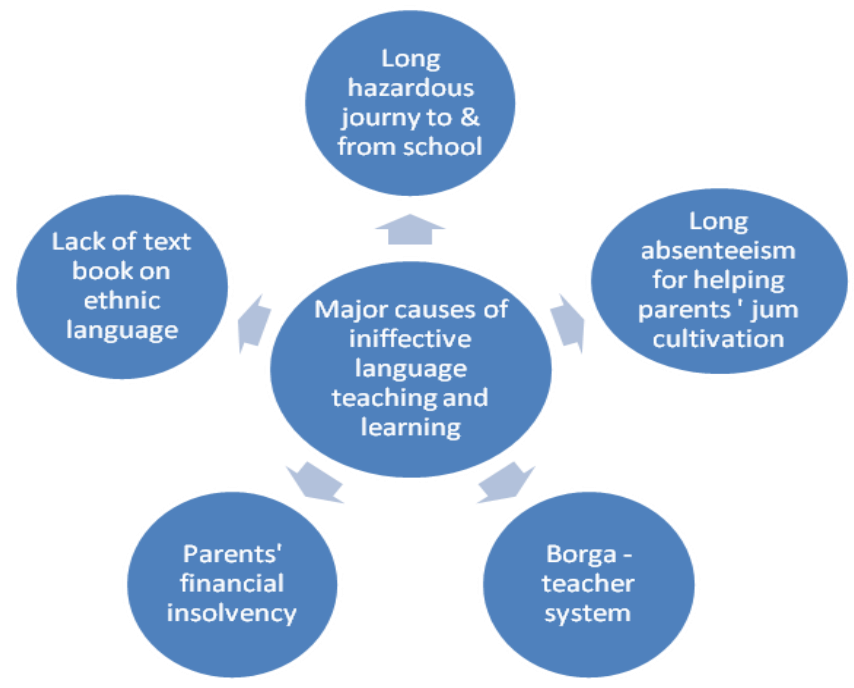

\section{CONClusion}

The study brings to focus some basic reasons which stand in the way of quality education of the children of indigenous people of CHTs. The main reasons are long tedious journey between home and educational institution, lack of dormitory, seasonal nature of parents' occupation (Jum cultivation), financial insolvency of guardians, lack of text books on mother tongues of the various ethnic groups and the prevalence of borga teacher system (replacement teacher).The teachers answered in the questionnaires that if the teachers are trained and sufficient materials like teaching aids multimedia, projector, video aids are available in the classrooms then they will feel comfortable and confident to teach their students in different languages. Also the students will become curious and attentive to their lessons. There are about 45 ethnic groups. Among them Chakma, Marma and Tripura community people are in great in numbers in CHTs. Parents told in this question that they gradually felt that without learning the Bengali language they cannot communicate with the mainstream population of Bangladesh. The major portion of Bengali people cannot understand them and in case of miscommunication there is a long gap between the indigenous and Bengali people. Also without learning English as it is an international language they cannot complete the global world. That is why they are bringing their children in schools to learn multiple languages. The curriculum planners 
(teachers) found that if the importance of multiple language teaching in education is guided properly the students from indigenous community can show their talents.

Students can be made happy to learn different languages if they get proper guideline. Because sometimes they do not get adequate care from the teachers who are appointed from mainstream as students of indigenous groups cannot speak in Bengali. In this case Bengali students who are from the mainstream population can develop their talents properly and can use the talents usefully. As a result, the indigenous students feel very shy and suffer from inferiority complex. Under this condition they feel it necessary to learn multiple languages.

\section{RECOMMENDATIONS}

The implication of these findings is that these issues need to be addressed. The students at primary, secondary and tertiary levels need dormitory facilities. There is a need of some arrangement to provide informal education when students accompany parents for JUM cultivation. NGOs are particularly required to find out some innovative idea and its implementation. Special attention is required to bring out text books on mother tongues as many ethnic tongues as possible. A strong foundation in the mother language provides a good bridge to learning a second language then Multilanguage effectively. It enables the learners to achieve competence and confidence. The learners of indigenous groups will be able to read and write their mother tongue and Bengali language fluently. They will be able to get access to more information and breaks in life. Simultaneously the learners will understand their own indigenous culture as well as Bengali culture and community.

Teaching aids can be provided through various government and non-government agencies. Activitybased curricula in primary, secondary and colleges should be followed for the learners. The text including clear, large and colourful will be very helpful for learning. It should also be prepared on the knowledge and experience that children bring to school which will help to remove the negative attitude to learn in Bengali. Parents also should be counseled about the need to learn in Bengali and English of their children so that they also can teach their children through their traditional stories, places and activities at their home.

Fund should be generated to publish the books in their mother tongue and should be included in their curricula.

Also if the students who got good marks can be trained to teach in pre-primary and primary level with their mother tongue. This process will guide the students to learn Bengali and English through their mother tongue.

If the government and with the NGOs come forewarned with greater assistance programs to help build boarding schools in different hilly areas it will be possible to address drop-out problem. If text books on indigenous languages are provided at least up to secondary levels along with lessening financial and accommodation problems, the indigenous children will be greatly benefitted.

Apart from these, problems of barga-teachers (replacement of trained regular teachers from plain land by untrained teachers from ethnic groups) were mentioned.

\section{ACKNOWLEDGEMENT}

The author expresses thanks to Prof. Dr. Ashraf Uddin Chowdhury, Dean of the Faculty of Business \& Economics, Bangladesh University for making important suggestions in preparing this paper

\section{REFERENCES}

[1] Bender, P., N. Dutcher, N., Klaus, D., Shore, J., \& Tesar, C. (2005). In their Own Language... Education for All. Education Notes, World Bank.

[2] Chakma, Aryamitro (2011), Chakma Sobdovandal, Khudro Nri-Gosthir Cultural Institute, Khagrachori, June.

[3] Marma, Aungzai (2011), Marma Dictionary, Khudro Nri-Gosthir Cultural Institute, Khagrachori, June.

[4] Oxfam (2014), Grassroots Voice: The situation of primary education in the Chittagong Hill Tracts of Bangladesh, Zabarang Kalyan Samity, Khagrachori, February. 
[5] Marma, Aungzai (2011), Marma Dictionary, Khudro Nri-Gosthir Cultural Institute, Khagrachori, June.

[6] Porishod, Local Govt. (1995), Tripura Vasa Shikhar Prothom Pat, Indigenous Cultural Institute, Rangamati, Reprint.

[7] Robinson,Joan and Lai, Sanjoy (2006), Method of Conducting Survey, Singapore.

[8] Sajjad, Sumon, (2011), Prokriti, Prantikota o Jatisottar Sahityo, Abohoman Prokashoni, Dhaka, February.

[9] Save the Children, (2009), Shikhoner Pothe, Save the Children UK, Bangladesh Programme.

\section{AUTHOR'S BIOGRAPHY}

Subarna Selim, worked in different English medium schools as an English Language Teacher.She is an associate Editor in Bangladesh University Digest. She attended a webinar and achieved the certificate from American Centre for Language, US Embassy, Bangladesh. She is studying in MPhil at Jahangirnagar University. She has three publications in ISSN journals.

\begin{tabular}{|c|c|c|}
\hline $\begin{array}{l}\text { 1.Some Motivational Tools for } \\
\text { Effective and Student }\end{array}$ & Bangladesh University Jo & $\begin{array}{l}\text { Vol.2, No.1, } 2015, \\
\text { ISSN: } 2309-8791\end{array}$ \\
\hline Friendly Teaching, & & \\
\hline $\begin{array}{l}\text { 2.A well designed activity } \\
\text { based learning for the young } \\
\text { Learners, }\end{array}$ & $\begin{array}{l}\text { Business-Review-Bangladesh, } \\
\text { Journal }\end{array}$ & $\begin{array}{l}\text { Vol. 3, No. 2, December } \\
\text { 2014, } \\
\text { ISSN: 2224-1884 }\end{array}$ \\
\hline 3.An Acculturation Model & ish Stu & Special Volume, December \\
\hline Based on Motivation for & Language, Literature \& & 2015 \\
\hline $\begin{array}{l}\text { Foreign Language Learning } \\
\text { in Bangladesh }\end{array}$ & $\begin{array}{l}\text { Community International } \\
\text { Conference }\end{array}$ & ISSN: 2071-1107 \\
\hline
\end{tabular}

At present she is working as an English Lecturer in the department of English at Bangladesh University. 